\title{
Mental health research: developing priorities and promoting its utilization to inform policies and services
}

\author{
M. Regan, ${ }^{1}$ R. Gater, ${ }^{2}$ A. Rahman ${ }^{3}$ and V. Patel ${ }^{1,4}$
}

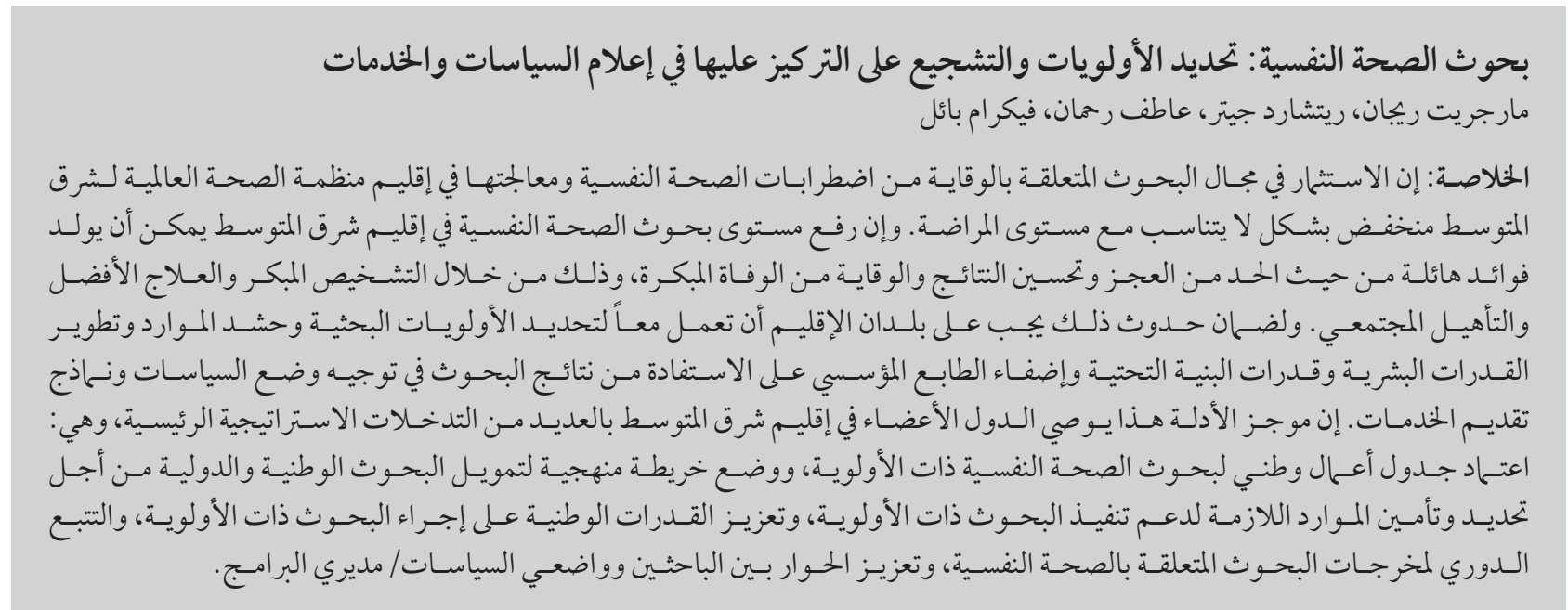

ABSTRACT Investment in research on the prevention and treatment of mental health disorders is disproportionately low in the WHO Eastern Mediterranean Region (EMR) relative to the disease burden. Scaling-up mental health research in the EMR could generate enormous returns in terms of reducing disability, improving outcomes and preventing premature death, through early diagnosis, better management and community-based rehabilitation. EMR countries must therefore work to identify research priorities, mobilize resources, develop human and infrastructure capacities and institutionalize use of research findings to guide development of policies and service delivery models. Several key strategic interventions for EMR Member States are recommended: adopt a prioritized national mental health research agenda; systematically map national and international research funding to identify and secure resources to support the implementation of the agenda; strengthen national capacity to undertake prioritized research; periodically map research output in mental health; and foster dialogue between researchers and policy-makers/programme managers.

Recherche en santé mentale : établissement de priorités et promotion de son utilisation pour orienter les politiques et les services

RÉSUMÉ L'investissement dans la recherche sur la prévention et le traitement des troubles de santé mentale est disproportionnellement faible dans la Région OMS de la Méditerranée orientale par rapport à la charge de morbidité. L'intensification de la recherche en santé mentale dans la Région de la Méditerranée orientale pourrait générer d'énormes retours en termes de réduction des incapacités, d'amélioration des résultats et de prévention des décès prématurés, au moyen du diagnostic précoce, d'une meilleure prise en charge et de la réadaptation communautaire. Les pays de la Région doivent œuvrer ensemble afin d'identifier les priorités de recherche, de mobiliser des ressources, de renforcer les capacités humaines et matérielles et d'institutionnaliser l'utilisation des résultats de recherche pour orienter l'élaboration de politiques et de modèles de prestation de services. Plusieurs interventions stratégiques clés pour les États Membres de la Région de la Méditerranée orientale sont recommandées : l'adoption d'un programme de recherche national en santé mentale ; la cartographie systématique du financement de la recherche national et international pour identifier et sécuriser les ressources à l'appui de la mise en œuvre du programme d'action ; le renforcement des capacités nationales permettant d'entreprendre une recherche par priorités ; la cartographie périodique des résultats de la recherche en santé mentale; et la promotion du dialogue entre chercheurs et responsables des politiques/des programmes.

${ }^{\prime}$ Centre for Global Mental Health, London School of Hygiene and Tropical Medicine, London, United Kingdom (Correspondence to M. Regan: magsregan@gmail.com). 2Institute of Brain, Behaviour and Mental Health, University of Manchester, and Lancashire Care NHS Foundation Trust, United Kingdom. ${ }^{3}$ Child Mental Health Unit, University of Liverpool, Alder Hey Children's NHS Foundation Trust, Liverpool, United Kingdom. ${ }^{4}$ Centre for Chronic Conditions and Injuries, Public Health Foundation of India, New Delhi, India. 


The need for EMR-
specific mental
health research

According to Professor Mahmoud Fathalla, former Chairman of the Advisory Committee on Health Research at the World Health Organization (WHO), "Research should not be considered as a luxury. On the contrary, health research is needed more when resources are scarce." There are several reasons that Region-specific research needs to be prioritized and undertaken. Mental health research is critical for guiding rational policy development, strategic programme planning and the reorganization of mental health services. Furthermore, evidence-based action can reduce the social impact and economic costs of mental disorders. A recent analysis by the World Economic Forum estimated that the cumulative global impact of mental disorders in terms of lost economic output will amount to US\$ 16 trillion over the next 20 years (1). However, the cost of researching mental health and subsequent treatment is often completely offset by the economic gains of implementing the findings of research. As an example, a United Kingdom report on the cost-efficiency of 15 evidence-based mental health interventions found that there was a significant return in investment for the government and other sectors, especially when tackling early identification and intervention (2). Regional research prioritizing early interventions could harness similar savings for governments, as well as tackling health inequities, decreasing disability and mortality, and ultimately fostering country development.

Although global priorities for mental health research have been established, Region-specific priorities need to be considered. The WHO Eastern Mediterranean Region (EMR) is a diverse group of countries, with vastly differing economic levels and health systems (3). A large proportion of its Member States are experiencing unrest and conflict, which makes it the ideal location for developing a comprehensive evidence base in the much neglected area of research on the effects of crises and conflicts on mental health.

\section{What is the current situation in the EMR?}

\section{Funding}

Globally, investment in research on the prevention and treatment of mental health disorders is disproportionately low in the EMR relative to the disease burden. Although there are no figures available on EMR countries' spending on mental health research, the regional average spend on research is $0.3 \%$ of gross domestic product (GDP), with $97 \%$ of the funding coming from government sources (4).

Although mental health has started to be recognized in the EMR as a public health priority in recent years, this has not yet translated into greater investment in research. Estimates show that $16.5 \%$ of the research-related activities in WHO Regional Office for the Eastern Mediterranean (EMRO) were focused on noncommunicable diseases and conflict health, even though these represent $59 \%$ of disability-adjusted lifeyears in the Region (5). There is some evidence that research output tracks GDP, but economic resources have been shown to not be the only factor responsible for health research outputs in the EMR (6).

In recent years, Grand Challenges Canada, an initiative funded by the Canadian Government, has begun investing heavily in mental health, by enabling learning, enhancing linkages, disseminating knowledge and leveraging resources, by supporting the development of the Mental Health Innovation Network. ${ }^{1}$ Unfortunately the EMR is currently under-represented in the allocation of project investment, as Table 1 shows, with only 4 projects located in the Region (3 in Pakistan and 1 in Afghanistan) (7). Other funding bodies that are also underrepresented in the Region include the Wellcome Trust, which is currently funding mental health research projects and programmes across Africa and Asia, but none in EMR countries.

\footnotetext{
Grand Challenges Canada has supported the development of the Mental Health Innovation Network, a global community for mental health innovators, which can be accessed at: http://mhinnovation.net
}

\begin{tabular}{|c|c|c|c|c|}
\hline Funding round & $\begin{array}{l}\text { No. of projects } \\
\text { globally }\end{array}$ & $\begin{array}{l}\text { No. of projects in } \\
\text { EMR }\end{array}$ & $\begin{array}{l}\text { Amount invested globally } \\
(\text { CAD } \times \text { millions })\end{array}$ & $\begin{array}{l}\text { Amount invested in EMR } \\
(\mathrm{CAD} \times \text { millions })\end{array}$ \\
\hline Round 1 & 14 & 2 & 19.4 & $2.00^{\mathrm{a}}$ \\
\hline Round 2 & 21 & 1 & 10 & 0.25 \\
\hline Round 3 & 22 & 1 & 7.7 & 0.27 \\
\hline Total & 57 & 4 & 28.1 & 2.52 \\
\hline
\end{tabular}

Source: Grand Challenges Canada (7)

${ }^{a}$ Estimate.

$C A D=$ Canadian dollars. 


\section{Capacity and human resources}

Promotion of a research environment at the university level and investment in research has been proposed by several studies previously, and this stands equally for research within mental health (8). EMRO is already supporting mentorships and fellowships within health, with 1417 fellowships for individuals from Member States supported during January 2006 and December 2010 in different fields of health (5). It is not clear, however, how many of these were related to mental health. An important step has been the establishment by the United States National Institute of Mental Health of Collaborative Hubs for International Research in Mental Health within 2 EMR countries, Afghanistan and Pakistan, forming part of the South Asian Hub for Advocacy, Research and Education on Mental Health (SHARE). ${ }^{2}$

The great majority of literature on mental health published in the leading international journals is derived from European and North American countries. Although publications from the EMR have steadily been rising in the past few decades, the Arab world produces only approximately $17 \%$ of the global average output of mental health publications per million population, which is comparable with countries of Latin American and the Caribbean. Between 1999 and 2006 publications originating from Arab nations that focused on mental health were only about $1 \%$ of the global figure of over 100000 publications for the same period (9).

\section{Prioritization}

The topics covered by country-specific mental health publications from the EMR shows that mood disorders, anxiety disorders and substance abuse have been most frequently researched (Table 2) (9). The majority of publications from Arab

More information on the SHARE

hub is available at: http://www.

centreforglobalmentalhealth.org/sites/ www.centreforglobalmentalhealth.org/ files/uploads/documents/BROCHURESHARE.pdf

Table 2 Specific mental health disorders addressed in country specific publications from the Eastern Mediterranean Region (EMR) between 1996 and 2005 (estimated $n=950^{\text {a }}$ )

\begin{tabular}{lc} 
Topic & \% of articles from EMR \\
Mood disorders & 14.1 \\
Anxiety disorders & 12.4 \\
Substance abuse disorders & 11.1 \\
Psychotic disorders & 4.4 \\
Mental retardation & 2.6 \\
Mental health services & 2.3 \\
Eating disorders & 2.2 \\
Suicide & 2.2 \\
Training of physicians in psychiatry & 2.0 \\
Personality disorders & 1.5 \\
Genetic studies of mental diversity & 1.5 \\
Sleep disorders & 1.1 \\
Diversity of determinants, services, cultural issues and & \\
psychometric properties of instruments & Remaining \\
\hline
\end{tabular}

Source: Jaalouk et al. (9).

The study did not include information from Afghanistan, Islamic Republic of Iran or Pakistan.

${ }^{a}$ An average of 95 country-specific publications produced during the decade suggests it was based on approximately 950 publications.

countries cited in the PubMed database between 1987 and 2002 were epidemiological (Table 3), and almost all were hospital-based (52\%) or community-based (37\%); only $4 \%$ were based in primary care (10).

Two research priority setting activities have been undertaken in recent years for mental health, one by members of the Lancet Mental Health Group (11) and another by the Mental Health and Psychosocial Support in Humanitarian Settings-Research Priority Setting project (12). These have highlighted the need for better alignment between researchers and practitioners, and concluded that it would be best to fill critical knowledge gaps by investing in research into 3 areas: health policy and systems; epidemiology; and improved delivery of cost-effective interventions.

Establishing mental
health research as a
priority: strategies

There are several key strategic interventions that need to be followed at a national and regional level to establish mental health research as a priority in EMR. These interventions - which are credible, feasible and cost-effectiveare summarized below:

\section{Adopt a prioritized national mental health research agenda}

Mental health must be highlighted as a research priority at the regional, national and institutional levels. Consideration should be given to supporting implementation research that informs the development of policies/programmes and service delivery models.

The criteria developed by the Lancet Mental Health Group (11) and the Mental Health and Psychosocial Support in Humanitarian SettingsResearch Priority Setting project (12) can be used by the EMR to develop specific priorities. The steps used by the Lancet group were:

- gathering technical experts and defining the context;

- creating a systematic list of research options; 


\begin{tabular}{lcc}
\hline $\begin{array}{l}\text { Table } 3 \text { Mental health publications from Arab countries distributed by type of } \\
\text { study, 1987-2002 }(\boldsymbol{n}=\mathbf{3 3 8})\end{array}$ & No. \\
\hline Type of study & 207 & 61.2 \\
Epidemiological & 36 & 10.7 \\
Psychometric & 35 & 10.4 \\
Clinical & 17 & 5.0 \\
Literature review & 16 & 4.7 \\
Basic science & 16 & 4.6 \\
Health systems research & 11 & 3.3 \\
Knowledge, attitudes and practice & 338 & $\mathbf{1 0 0 . 0}$ \\
Total & & \\
\hline
\end{tabular}

Source: Afifi (10).

- scoring listed research options against explicit criteria, for example: likely to generate new knowledge in an ethical way; likely to be efficacious and effective; likely to reduce the burden of disease; likely to be affordable, deliverable and sustainable; predicted effect of intervention on equity;

- addressing stakeholders' values; and

- undertaking programme budgeting, marginal analysis and advocacy.

Alternatively, the 6 goals developed for establishing the Grand Challenges Canada can be used by countries to guide the prioritization agenda (7):

- Goal A: Identify root causes, risks and protective factors;

- Goal B: Advance prevention and implementation of early interventions;

- Goal C: Improve treatments and expand access to care;

- Goal D: Raise awareness of the global burden;

- Goal E: Build human resource capacity;

- Goal F: Transform health-system and policy responses.

\section{Systematically map national \&} international research funding to identify and secure support

- Clear mapping of what is being spent nationally and regionally on mental health research needs to be undertaken, and EMR countries should have evidence of return on investment to secure additional financial support by development partners and sectors other than health. The World Bank, regional development banks, national development agencies, nongovernmental agencies and other foundations could be potentially targeted.

- It is important to enhance the quality of research in the Region by investing in cost-effective operational and implementation research, based on the nationally and regionally defined priorities. Greater representation within international journals will draw attention and funding to the defined national priority agenda.

Resources other than finance should be pursued. Ethically sourced human, educational and infrastructural resources are all necessary components to stimulate mental health research.

\section{Enhance national capacity to undertake prioritized research}

The single most important factor is the shortage of trained researchers in the EMR. Opportunities for training and supervision in research are limited. To combat this shortage and the risk of "brain-drain" of trained researches, research must be given a higher priority and become a well-established and resourced area within the EMR. ESSENCE on Health Research, a collaborative initiative of the WHO Special Programme for Research and Trainingin Tropical Diseases, has developed a guiding document that incorporates current knowledge and best practice on health research capacity to form clear principles that can be used by EMR countries to make effective decisions (13).

- Individual countries need to establish research-orientated training programmes linked with ongoing project collaborations within the Region, and liaise with established institutions in other regions that are strong in the area of mental health research, to support capacity building initiatives with short-term staffloans and sabbaticals. See the case study on the SHARE initiative for an example of research collaboration within South Asia (Box 1).

\section{Periodically map the research output in mental health}

- A bank of validated mental health research needs to be established in EMR, for researchers to contribute to and decision-makers to consult systematically (for example through a regional hub of the Mental Health Innovation Network).

\section{Foster dialogue between researchers and decision- makers}

- Communication between mental health researchers and decisionmakers in EMR needs to improve, with stronger more formalized communication taking place between researchers, health managers, planners, civil society, donors and policy-makers. This should be fostered by knowledge management and translation activities to facilitate the sharing of evidence of mental-health-reach with relevant policy-makers. Decisionmakers must be made aware of the importance that evidence can play in sound policy-making. For this to happen, it is vital that decision-makers are orientated on how research is undertaken, how to evaluate its quality and how to utilize it in decision-making efficiently. This will facilitate the exchange of information on successful initiatives and innovative activities, both within and outside the Region. 


\section{Box 1 Case study of research collaboration in mental health research by the South Asian Hub for Advocacy, Research and Education on Mental Health (SHARE)}

SHARE is a multi-country network of institutions in South Asia, created to support mental health research throughout its region (14). Since 2011, SHARE has brought together researchers and practitioners from 16 organizations across 6 countries in South Asia.

The objective of this hub are to generate evidence for affordable and effective interventions for treatment of mental disorders, to increase mental health capacity to address relevant policy questions and to foster the uptake of mental health research into policy and practice.

SHARE is implemented through a partnership between academic leaders in global mental health, innovators in mental health services research, civil society stakeholders and policy-makers. SHARE is one of the Collaborative Hubs for International Research on Mental Health funded by the National Institute of Mental Health in the United States of America.

\section{References}

1. Bloom DE, Cadiero ET, Jane-Llopis E, Abrahams-Gessel S, Bloom $L R$, Fthima $S$, et al. The global economic burden of non-communicable diseases. Geneva: World Economic Forum; 2011.

2. McDaid D, Parsonage M, Knapp M. Mental health promotion and mental illness prevention: the economic case. London: Department of Health; 2011.

3. Health systems strengthening in countries of the Eastern Mediterranean Region: challenges, priorities and options for future action. Cairo: World Health Organization, Regional Office for the Eastern Mediterranean; 2013.

4. Arab human development report. New York: United Nations Development Programme; 2009.

5. Strategic direction for scaling up research for health in the Eastern Mediterranean Region. Cairo: World Health Organization, Regional Office for the Eastern Mediterranean; 2011.

6. Bridging the gap between health researchers and policymakers in the Eastern Mediterranean Region. Technical paper. Cairo: World Health Organization, Regional Office for the Eastern Mediterranean; 2008 (EM/RC55/4).

7. Global mental health [Internet]. Grand Challenges Canada (http://www.grandchallenges.ca/grand-challenges/globalmental-health, accessed 27 May 2015).

8. Adams JE, King C, Pendlebury D, Hook D, Wilsdon J. Global research report Middle East: exploring the changing landscape of Arabian, Persian and Turkish research. London: Evidence (Thomson Reuters); 2011.
9. Jaalouk D, Okasha A, Salamoun MM, Karam EG. Mental health research in the Arab world. Soc Psychiatry Psychiatr Epidemiol. 2012 Nov; 47(11):1727-31. PMID:22388974

10. Afifi MM. Mental health publications from the Arab world cited in PubMed, 1987-2002. East Mediterr Health J. 2005 May;11(3):319-28. PMID:16602450

11. Tomlinson M, Rudan I, Saxena S, Swartz L, Tsai AC, Patel V. Setting priorities for global mental health research. Bull World Health Organ. 2009 Jun;87(6):438-46. PMID:19565122

12. Tol WA, Patel V, Tomlinson M, Baingana F, Galappatti A, Silove $\mathrm{D}$, et al. Relevance or excellence? Setting research priorities for mental health and psychosocial support in humanitarian settings. Harv Rev Psychiatry. 2012 Jan-Feb;20(1):25-36. PMID:22335180

13. Seven principles for strengthening research capacity in low and middle-income countries: simple ideas in a complex world. Essence Good Practice Document Series. Geneva: ESSENCE on Health Research, World Health Organization Special Programme for Research and Training in Tropical Disease; 2014 (http://www.who.int/tdr/publications/Essence_report2014_OK.pdf, accessed 27 May 2015).

14. SHARE South Asian Hub for Advocacy, Research and Education on Mental Health [Internet] (http://www.centreforglobalmentalhealth.org/sites/www.centreforglobalmentalhealth.org/ files/uploads/documents/BROCHURE-SHARE.pdf, accessed 27 May 2015). 